\title{
Regulation of PepT1 by leptin and physiological implications
}

Patrick Hindlet, Marion Buyse.

Faculté de Pharmacie, Laboratoire de Pharmacie Clinique, EA 4123, Université Paris SUD-XI.

The small intestine is the major site of nutrient absorption, under physiological conditions dietary proteins entering the small intestine are degraded by hydrolytic enzymes in a mixture of free amino acids and small peptides, mainly di- and tripeptides which are efficiently absorbed by enterocytes. In fact, $70 \%$ of the nitrogen supply is provided by the absorption of these oligopeptides that is ensured by the proton-dependent transporter PepT1 (Adibi 1997).

PepT1 is a 12 membrane-spanning domains protein expressed in the brush border membrane of enterocytes in the small intestine, with an increased expression at the villous tip. The $\mathrm{H}^{+}$gradient, the driving force of PepT1, is maintained by the $\mathrm{Na} / \mathrm{H}^{+}$exchanger (NHE3), located in a close vicinity to PepT1 at the apical membrane.

Therefore PepT1 plays a key role in the regulation of nitrogen supply but also in drug bioavailability. Indeed many peptidomimetic drugs such as $\beta$ lactam antibiotics, angiotensin converting enzyme inhibitors and antiviral prodrugs are synthesized to be transported by PepT1 that ensures a maximal absorption.

Whithin the past few years, many studies have focused on the identification of factors regulating the expression and activity of PepT1. For example, under physiological conditions, feeding or circadian rhythm constitute major regulators of the oligopeptide transport activity. Moreover, intestinal absorption of oligopeptides via PepT1 was demonstrated to be altered by diseases affecting the intestinal tract or by nutritional and metabolic disorders such as diabetes.

Indeed, in rats, streptozotocin injection induced-diabetes, increases the activity of PepT1 in the brush border membrane of the small intestine as the consequence of the augmented abundance of this transporter by the stabilization of mRNA encoding PepT1 (Gangopadhyay et al. 2002). In contrast two other studies reported a decrease (Bikhazi et al. 2004) or no modification (Watanabe et al. 2003) of dipeptides uptake in type 1 diabetes. The discrepancy between these results was not clearly accessed. However in vitro experiments demonstrated that a short time treatment with insulin enhances PepT1 activity by recruiting the preformed intracellular pool of the transporter to the brush border of the enterocytes without any change in mRNA PepT1 expression (Thamotharan et al. 1999). On the other hand, in 2 models of type 2 diabetes, 1) the hyperglycemic, hyperinsulinemic non-obese insulino-resistant GK rats or 2) the obese insulino-resistant Zucker rats, an increase in PepT1 activity and expression at the brush border membrane were observed (Watanabe et al. 2003). Therefore, insulin seems to regulate PepT1 at the post-transcriptional level after both short and long term exposition.

Another hormone, namely leptin, is involved in the PepT1 regulation during metabolic disorders observed in diabetes and obesity.

\section{PepT1 regulation by Leptin}

Leptin, the $o b$ gene product was initially reported to be produced exclusively by adipose cells; it is released into the circulation and transported across the blood brain barrier into hypothalamus where it activates specific leptin receptors (Ob-Rs) that regulate energy homeostasis by matching energy intake and expenditure.

Subsequent studies have shown that leptin is also produced by non adipose tissues including stomach. Unlike adipocyte-leptin, stomach-derived leptin is rapidly secreted both into the blood and the gastric lumen after feeding (Bado et al. 1998). In addition part of the leptin secreted in the gastric juice escapes proteolysis degradation thanks to its binding to its soluble receptor Ob-Re. Then the biologically active hormone can initiate physiological processes in the intestine since the presence of $\mathrm{Ob}-\mathrm{Rs}$ has been demonstrated along the digestive tract. 
Leptin secreted by chief cells in the gastric juice promptly induces membrane insertion of PepT1 from a preformed cytoplasmic pool and so rapidly increases nitrogen supply absorption (Buyse et al. 2001). By contrast, leptin produced by adipocytes gradually regulates PepT1 (Hindlet et al. 2007) at the transcriptional level via the ERK pathway and at the translational level mediated by the ribosomal protein S6 activation. However this activation was systematically followed by a time and dose dependent loss of leptin action reflecting a desensitisation phenomenon (Hindlet et al. 2009).

Moreover, two in vivo models of metabolic syndromes (the ob/ob mice or the diet-induced obesity mice) characterized by leptin signalization impairment, were associated by a drastic PepT1 down regulation.

These results suggest that leptin, like insulin, induces PepT1-mediated oligopeptide transport after a short term exposition, but also triggers the production of a newly synthesized pool of PepT1 afterwards.

Implication of PepT1 on the feedback regulation of gastrointestinal function and food intake

It is well known that high protein diets induce satiety and are commonly used in some weight reduction programs. These effects on body weight homeostasis could be based on various hypotheses.

First, it has been shown that oligopeptides efficiently transported by PepT1, induce a $\mathrm{Ca}^{2+}$-dependent CCK secretion that stimulates vagal afferent fibers discharge mediated by CCK1 receptor to reduce gastric motility and emptying and produce satiety signal (Cordier-Bussat et al. 1998; Darcel et al. 2005; Murai et al. 2000). This CCK secretion could be due to the interaction of oligopeptides with PepT1 expressed either on the absorptive enterocytes or directly on CCK secreting endocrine cells, however no evidence for the expression of PepT1 on I Cells in vivo has been provided so far.

The second hypothesis in the implication of PepT1 in the feedback regulation of food intake is the cross talk between PepT1 and glucose transporters.

RS1 is an intracellular protein that mediates transcritpionnal and post transcriptional downregulation of the $\mathrm{Na}^{+}-$ glucose cotransporter SGLT1. In fact 2 tripeptides, QCP and QSP, substrates of PepT1, were identified to carry RS1 activity. Orally applied QSP in rats, absorbed by PepT1 can be used to downregulate small intestinal glucose absorption, and more importantly, related compounds could constitute potential drugs for the treatment of type 2 diabetes (Vernaleken et al. 2007).

On the other hand, glucose and artificial sweetener inhibit PepT1 mediated transport by the activation of a sweet taste receptor through a PKC $\beta$ II dependant pathway (Mace et al. 2007).

Finally intestinal di- and tripeptide transporter could contribute to the regulation of lipid storage. Indeed uptake of free fatty acids into intestinal epithelial cells is strongly dependent on the alteration in intracellular $\mathrm{pH}$ which is normally regulated by the interplay of PepT1 and the $\mathrm{Na}^{+} / \mathrm{H}^{+}$exchanger NHE3. Loss of PepT1 decreases intestinal proton influx leading to higher uptake of free fatty acids with fat accumulation and thus fat phenotype; whereas loss of NHE3 causes intracellular acidification by PepT1-mediated proton/dipeptide symport and thus induces a lean phenotype (Spanier et al. 2009).

Thus it appears that the crosstalk between nutrient and transporters (among them) adjusts the absorptive capacity of the gastrointestinal tract to ensure efficient digestion and absorption of a meal in the postprandial period and to control energy homeostasis. 


\section{REFERENCES}

Adibi SA (1997) The oligopeptide transporter (Pept-1) in human intestine: biology and function. Gastroenterology 113:332-40.

Bado A, Levasseur S, Attoub S, Kermorgant S, Laigneau JP, Bortoluzzi MN, Moizo L, Lehy T, Guerre-Millo M, Le Marchand-Brustel Y and Lewin MJ (1998) The stomach is a source of leptin. Nature 394:790-3.

Bikhazi AB, Skoury MM, Zwainy DS, Jurjus AR, Kreydiyyeh SI, Smith DE, Audette K and Jacques D. (2004) Effect of diabetes mellitus and insulin on the regulation of the PepT 1 symporter in rat jejunum. Mol Pharm 1:300-8.

Buyse M, Berlioz F, Guilmeau S, Tsocas A, Voisin T, Peranzi G, Merlin D, Laburthe M, Lewin MJ, Roze C and Bado A (2001) PepT1-mediated epithelial transport of dipeptides and cephalexin is enhanced by luminal leptin in the small intestine. J Clin Invest 108:1483-94.

Cordier-Bussat M, Bernard C, Levenez F, Klages N, Laser-Ritz B, Philippe J, Chayvialle JA and Cuber JC (1998) Peptones stimulate both the secretion of the incretin hormone glucagon-like peptide 1 and the transcription of the proglucagon gene. Diabetes 47:1038-45.

Darcel NP, Liou AP, Tome D and Raybould HE (2005) Activation of vagal afferents in the rat duodenum by protein digests requires PepT1. J Nutr 135:1491-5.

Gangopadhyay A, Thamotharan M and Adibi SA (2002) Regulation of oligopeptide transporter (Pept-1) in experimental diabetes. Am J Physiol Gastrointest Liver Physiol 283:G133-8.

Hindlet P, Bado A, Farinotti R and Buyse M (2007) Long-term effect of leptin on h+-coupled Peptide cotransporter 1 activity and expression in vivo: evidence in leptin-deficient mice. J Pharmacol Exp Ther 323:192-201.

Hindlet P, Bado A, Kamenicky P, Delomenie C, Bourasset F, Nazaret C, Farinotti R and Buyse M (2009) Reduced intestinal absorption of dipeptides via PepT1 in mice with diet-induced obesity is associated with leptin receptor down-regulation. J Biol Chem 284:6801-8.

Mace OJ, Affleck J, Patel N and Kellett GL (2007) Sweet taste receptors in rat small intestine stimulate glucose absorption through apical GLUT2. J Physiol 582:379-92.

Murai A, Noble PM, Deavall DG and Dockray GJ (2000) Control of c-fos expression in STC-1 cells by peptidomimetic stimuli. Eur J Pharmacol 394:27-34.

Spanier B, Lasch K, Marsch S, Benner J, Liao W, Hu H, Kienberger H, Eisenreich W and Daniel H (2009) How the intestinal peptide transporter PEPT-1 contributes to an obesity phenotype in Caenorhabditits elegans. PLoS One 4:e6279.

Thamotharan M, Bawani SZ, Zhou X and Adibi SA (1999) Hormonal regulation of oligopeptide transporter pept-1 in a human intestinal cell line. Am J Physiol 276:C821-6.

Vernaleken A, Veyhl M, Gorboulev V, Kottra G, Palm D, Burckhardt BC, Burckhardt G, Pipkorn R, Beier N, van Amsterdam C and Koepsell H (2007) Tripeptides of RS1 (RSC1A1) inhibit a monosaccharide-dependent exocytotic pathway of Na+-D-glucose cotransporter SGLT1 with high affinity. J Biol Chem 282:28501-13.

Watanabe K, Terada K and Sato J (2003) Intestinal absorption of cephalexin in diabetes mellitus model rats. Eur J Pharm Sci 19:91-8. 